\title{
Reviewing Diversity Training: Where We Have Been and Where We Should Go
}

\author{
KATERINA BEZRUKOVA \\ Santa Clara University \\ KAREN A. JEHN \\ Melbourne Business School \\ CHESTER S. SPELL \\ Rutgers University
}

\begin{abstract}
We review and critically examine 178 articles whose authors have investigated numerous aspects of diversity training programs on campuses and in the workplace. We first examine the characteristics of the research, including sample, study method, and theoretical framework. Consistent with the training framework of Baldwin and Ford (1988) and Blume and colleagues (2010), we then organize the articles by the context of training, training design, trainees' characteristics, and training outputs. Although we found a myriad of different forms, shapes, and combinations of diversity training in terms of its design elements, some programs (e.g., integrated training) were relatively rare, yet authors viewed them more positively than other programs (e.g., stand-alone training). We discuss gaps in the literature and provide suggestions for future research on diversity training.
\end{abstract}

The U.S. Equal Employment Opportunity Commission (EEOC) reported 99,992 workplace discrimination filings in the private sector during the 2010 fiscal year, representing an all-time high (EEOC Reports, 2011). This suggests that discrimination on the basis of age, race, gender, and other factors remains a major workplace problem despite the civil rights and related social movements of the past few decades. As a response to this social issue, diversity training has the potential to make a huge, positive impact because the idea behind it

Address all correspondence to Katerina Bezrukova, Psychology Department, Santa Clara University, 500 El Camino Real, Santa Clara, CA 95053.E-mail: ybezrukova@scu.edu

This research was supported by the Alfred P. Sloan Foundation, The BOLD Initiative, SEI Center for Advance Studies in Management of the Wharton School, The George Harvey Program on Redefining Diversity: Value Creation through Diversity, and the Solomon Asch Center for the Study of Ethnopolitical Conflict at the University of Pennsylvania. We would like to thank Aparna Joshi for her comments on earlier drafts of this paper and Michelle Campion and students from the "Managing A Diverse Workforce" course at Santa Clara University for helping with additional data collection. is to address prejudice, stereotyping, and other biases (King, Dawson, Kravitz, \& Gulick, 2010a). Not surprising then, is that scholars of diversity have given a generous amount of attention to this important topic, summarizing prior studies to provide some guidelines for successful implementation of diversity training (e.g., Curtis, Dreachslin, \& Sinioris, 2007; Ely, 2004a; Kalev, Dobbin, \& Kelly, 2006; Kulik \& Roberson, 2008a, 2008b; Paluck, 2006). Although diversity training programs have been widely used, some have raised critical questions about their quality and methods. Several authors have pointed out that there is still much to learn about diversity training, even given the increasing number of studies in organizational and educational settings (Combs \& Luthans, 2007; Hite \& McDonald, 2006; Wiethoff, 2004).

Our objectives are to obtain a comprehensive understanding of the current state of knowledge regarding diversity training by identifying its relevant design elements, examining the qualitative nuances of its effects, and informing its research and the practice. We build on prior analytic work 
and, in contrast to past studies that focused on one industry (e.g., health core, Curtis et al., 2007), include research conducted across multiple industries (e.g., financial, insurance, manufacturing, etc.) and on campuses. We also expand on prior reviews of diversity training (e.g., Kulik \& Roberson, 2008a) by including both qualitative and quantitative studies, and thus, consider a larger number of studies than were previously examined (Curtis et al., 2007; Kulik \& Roberson, 2008a). In line with this previous work and following the prominent work of others in diversity research (Jackson, Joshi, \& Erhordt, 2003; Paluck, 2006; Williams \& O'Reilly, 1998), we chose a narrative review approach that focuses on the critical points of current knowledge, including findings as well as theoretical and methodological contributions to diversity training research. As exemplified by Posthuma, Morgeson and Campion (2002: 3), a narrative review can describe and critique the research methodology of the studies reviewed in detail: "[I]t can include which specific predictors related to which specific criterion are examined, in what settings, when the effects are not found and so on. In doing so, we first focus on the characteristics of the research on diversity training, including sample, study method, and theoretical framework.

Further, existing training and development approaches emphasize that training program effectiveness flows from needs assessment, to design and implementation, to evaluation (e.g., Goldstein \& Ford, 2002; Noe, 2010; Werner \& DeSimone, 2009). Recent reviews of the literature on needs assessment in diversity training shed light on many important connections between that and diversity training design (Roberson, Kulik, \& Pepper, 2003). However, as Kulik and Roberson (2008a) pointed out, no research has focused on understanding the implications of different design characteristics of diversity training. In response, and following Holladay, Knight, Paige, and Quinones' (2003) call for more systematic work to better understand the unique value of different elements of diversity training within a broader view, we examine the main constructs that appear in the studies on diversity training (e.g., training context, design elements, participant characteristics, outcomes of diversity training) and organize them according to the training framework of Blume and colleagues (2010) and Baldwin and Ford (1988).

\section{DIVERSITY TRAINING}

Diversity training is defined as a distinct set of programs aimed at facilitating positive intergroup interactions, reducing prejudice and discrimina- tion, and enhancing the skills, knowledge, and motivation of people to interact with diverse others (Pendry, Driscoll, \& Field, 2007). Diversity training differs from other types of training because it challenges the way one views the world and deals with issues that may seem emotional or subjective (Hanover \& Cellar, 1998; Law, 1998). Since attitudes toward diversity are likely formed before training, diversity training tends to be more emotionally and politically charged than many other types of training (Alderfer, 1992; Paluck, 2006). Yet, the goals of most diversity training programs include compliance, harmony, inclusion, justice, and transformation (Rossett \& Bickham, 1994). According to Simons (1992), these goals ultimately can contribute to the welfare of all involved in the interaction because (1) individuals become more satisfied due to positive work or social climates (Combs \& Luthans, 2007); (2) diverse groups can be more effective and generate more new ideas for innovation (cf. Williams \& O'Reilly, 1998); and (3) organizations can also obtain a competitive advantage due to less turnover, better coordination of information, more client relations, fewer EEO law suits, and so on (Naff \& Kellough, 2003). Overall, the key objective of diversity training is for people to learn how to work effectively with different others which may increase overall success for both organizations and individuals.

In line with Posthuma et al., (2002), we conducted a narrative review, which allowed us to critically examine the research on diversity training, generate recommendations for future research, show how these recommendations derive from past research, and highlight limitations in the literature (see, e.g., Jackson et al., 2003; Paluck, 2006; Williams \& O'Reilly, 1998). Also, we believe the narrative review provides guidance for educators, consultants, and managers alike on what types of programs have been studied and their outcomes. We do so because research has made significant progress in assessing the methodological rigor of existing research on diversity training (Paluck \& Green, 2009), yet it did not integrate these assessments with specific training context and design elements of diversity training. We thus extended this literature by including these important characteristics. In our review of the diversity training literature, we also built on the more general training literature and, in line with Baldwin and Ford (1988) and more recently Blume (2010), organized the studies by diversity training inputs and shortand long-term outputs. Training outputs include trainee reactions and affective or attitudinal, cognitive, and behavioral learning outcomes (Kraiger, Ford, \& Salas, 1993). Recent research on diversity 
training has been very informative in summarizing the outcomes of diversity training progroms (Kulik \& Roberson, 2008a), yet has not paid much attention to its short- and long-term consequences and even less attention to training inputs.

Training inputs include training context, training design, and trainee characteristics (Baldwin \& Ford, 1988; Blume, 2010). Although the context of training, such as academic versus organizational settings, has been recognized in the literature on diversity training (Kulik \& Roberson, 2008a), we extend this work to also consider, for example, the training approach (stand-alone vs. integrated with other organizational practices), and training attendance (mandatory vs. voluntary). Prior literature on diversity training (e.g., Abbott, 2008; Flynn, 1998; Kulik \& Roberson, 2008a; Paluck, 2006) noted some of these aspects separately, but reviews have not to this point integrated these into an overall framework. Similarly, certain characteristics of the diversity training design have been discussed independently (e.g., group-specific vs. inclusive focus and awareness vs. skills-based training types; Kulik \& Roberson, 2008b; Roberson, Kulik, \& Pepper, 2003), but never brought together with other important aspects of diversity training (e.g., training context). Finally, we build on prior work that considered the composition of the training groups themselves (Roberson, et al., 2003) to summarize studies on diversity training programs and what we know about them. Thus, our framework brings together critical components of diversity training that up until now have been discussed one by one or ignored all together. This framework acts as an integrative mechanism by situating previous research in a larger research context and identifying gaps in the literature.

\section{Criteria for Study Inclusion}

We performed data-based searches through ABIInform, PsychINFO, Psychological Abstracts, Dissertation Abstracts International, and the Education Resource Information Center (ERIC). To capture the broadest possible sample of relevant articles, we used multiple search terms, including all words beginning with the roots "diverse," "culture," "multicultural," "cross-cultural," "pluralism," "prejudice," "bias," "stereotype," "race," "racial," "ethnic," "ethnicity," "Lesbian Gay Bi-sexual and Transgender (LGBT)," "gay," "age," "generational," "women," and "gender." We crossed these terms with training-related search words, such as "train," "workshop," "education," "course," "intervention," "program," "initiative," "teach," and "instruct." To reduce inadvertent omissions, different members of the research team searched the databases annually from March 2000 to March 2011. We also manually examined the reference sections of past reviews and studies to find articles not identified in the database searches. In addition to searching the Dissertation Abstracts International database, we conducted a manual search for articles that might not have been published yet or were not available electronically (1975-2011). Diversity researchers identified from the published papers were also contacted by e-mail, and copies of unpublished papers and dissertations were requested when necessary (these eventually accounted for $9 \%$ of the included reports). A total of 178 articles were identified for review; these included quantitative studies $(N=124)$, studies based on qualitative methodology $(N=12)$, and nonempirical work that included review papers, measurement articles, book chapters, and theory papers $(N=42)$.

We first examined the characteristics of the research (e.g., samples, theories), and then organized the research into broad categories (e.g., training context; see Tables 1 \& 2) consistent with prior research on training (Baldwin \& Ford, 1988; Blume, 2010). We adopted the technique of narrative analysis, beginning by reading the text and analyzing it by identifying emergent themes within each category (e.g., educational vs. workplace settings within training context). Next, two authors independently coded the articles with respect to a theme. The vast majority of studies were coded similarly by both coders (interrater agreement $=97.6 \%$ ). Next, the two authors met to resolve coding discrepancies. They each discussed their rationale for how they coded the articles. After discussing their differences, they agreed upon the best coding for the articles. No major discrepancies were found across the raters. This analysis confirmed previously identified themes and categories (e.g., context, design, trainee characteristics) in prior diversity training research and was also consistent with the more general training literature (e.g., Goldstein \& Ford, 2002; Noe, 2010; Roberson et al., 2003; Werner \& DeSimone, 2009). We thus first provided an analytic overview of the research on diversity training and then discussed each category. Within each category, we defined themes that emerged from our analysis of the articles (e.g., training approach as mandatory or voluntary) and reviewed associated literature. Here, we focused on contrasts between the different themes within categories (e.g., integrated vs. stand-alone training approach). Second, we summarized findings respective to these themes and provided suggestions for future research. We also provided a description 
of an exemplar study within each category of our framework.

\section{Characteristics of the Research}

The first category in our framework is the characteristics of the research undertaken to study diversity training. Here we report on the samples used in studies, research designs, and theoretical frameworks used to explain diversity training effects. Turning first to study samples, a variety of settings were represented, and these included public, private, and student samples (see Table 1). In particular, research settings have included governmental agencies (Sanchez \& Medkik, 2004); schools (Law, 1998; McCauley, Wright, \& Harris, 2000); and universities (Astin, 1993; Pascarella, Edison, Nora, Hagedorn, \& Terenzini, 1996; Stroup, 1998), as well as the corporate sector (ChrobotMason, 2004; Combs \& Luthans, 2007; De Meuse, Hostager, J., \& O'Neill, 2007; Hanover \& Cellar, 1998). Second, with respect to the study methodologies of empirical work, four groups of research methods have been uncovered in our review: studies using survey-based methods $(N=87)$, quasiexperimental work $(N=16)$, experimental studies $(N=19)$, and case studies $(N=12$; see Table 1$)$. Some studies have surveyed respondents on the characteristics of diversity programs across organizations, such as Konnert Dobson, and Watt's (2009) investigation of the extent to which doctoral and internship programs considered age as an aspect of diversity.
Finally, as our review shows, the dominant theoretical framework across many diversity training studies has been the multicultural tradition. This perspective emphasizes a number of developmental stages through which trainees are assumed to progress to attain intercultural sensitivity (e.g., Bennett, 1993). For instance, Pedersen's (2010) study used a developmental model of intercultural sensitivity to assess diversity program effectiveness for university students. Another framework that has also received attention in the literature on diversity training utilizes the principles of social identity and social categorization theories (Tajfel \& Turner, 1986) and contact research (Allport, 1954). According to these frameworks, the effects of diversity training can be predicted based on the interplay of positive (recognition and appreciation of cultural differences) and negative (racial, ethnic and religious prejudice and discrimination) intergroup attitudes resulting from the saliency of the trainee's identity. Further, intergroup contact under the right conditions may increase the perception of similarity and promote liking (Allport, 1954; Gaertner et al., 1999; Pettigrew, 1998). Equal status, personal contact, cooperation for shared goals, development of intergroup norms that support constructive interaction, and institutional support for contact are important conditions affecting the outcome of contact and thus effectiveness of the diversity training program. Below we report several issues with this body of research that emerged from our review.

TABLE 1

Characteristics of Diversity Training Research

\begin{tabular}{|c|c|c|}
\hline & Characteristic & $N$ \\
\hline \multirow{4}{*}{ Sample ${ }^{\alpha}$} & Public & 28 \\
\hline & Private & 18 \\
\hline & Multiple samples & 4 \\
\hline & Not specified & 24 \\
\hline \multirow[t]{5}{*}{ Study methodology } & Survey & 87 \\
\hline & Case studies & 12 \\
\hline & Multiple methodologies & 5 \\
\hline & Literature review & 14 \\
\hline & Other nonempirical work & 28 \\
\hline \multirow{2}{*}{ Theoretical framework ${ }^{\mathrm{b}}$} & Multicultural & 40 \\
\hline & Stand-alone or in concert with other theories & 23 \\
\hline
\end{tabular}

\footnotetext{
${ }^{\alpha}$ Numbers do not add up to 178 because 42 articles were nonempirical and some articles contain multiple settings.

${ }^{\mathrm{b}}$ Numbers do not add up to 178 because some articles contained multiple theoretical frameworks.
} 
Of the studies we reviewed, 24 did not report sample characteristics (e.g., sample size). Consequently, important questions remain, such as the extent to which trainees' characteristics reflect the organizations in which the training took place, whether there are similarities in outcomes between management and student trainees, or whether differences exist between unskilled and professional personnel participating in the training. Future research should attempt to answer these questions.

Studies that we reviewed were also limited with respect to study design; in some cases no baseline was established for participants' outcomes (e.g., Chrobot-Mason, 2004; Ellis \& Sonnenfeld, 1994; Kracht, 1998); others utilized pre-posttest design but over different groups of people (e.g., GuyWalls, 2007). More emphasis, thus, should be directed toward conducting studies employing more robust experimental and longitudinal field research designs as well as reporting enough data to calculate effect sizes to make a formal meta-analysis feasible. Most studies have also been based on self-reports and have been collected from a single source. These subjective, explicit, and often single-item measures have well-known measurement limitations, such as unknown reliabilities and a potential for response bias due to a participants' lack of introspection (Asendorpf, 2002) and possible motivation to distort responses (Orne, 1962; Rosenberg, 1969). More objective measures (e.g., application of peers' evaluations, observations, and behavioral or physiological measures in addition to traditional direct self-reports) should be considered. Result-oriented measures, such as lawsuits, grievances, turnover, bonuses, recruitment of minorities, and so on within the same organization may also be beneficial. ${ }^{1}$

While a variety of scales have been used in evaluating the effects of diversity training (e.g., Multicultural Counseling Inventory (MCI), Attitudes Towards Inclusive Education scale (ATIES), we found that some studies used scales such as the Multicultural Awareness, Knowledge, and Skills Survey (MAKSS; D’Andrea, Daniels, \& Heck, 1991) designed to examine awareness of one's attitudes toward ethnic minorities, knowledge concerning minority populations, and cross-cultural communication skills, and the Modern Racism scale (McConahay, 1981) used to assess explicit

\footnotetext{
${ }^{1}$ We would like to thank an anonymous reviewer for this suggestion. This is also what Kirkpatrick and Kirkpatrick (2006) and Phillips (1996) have labeled as a "results-level" evaluation of training. Notably, it is rare to see "results-level" data for diversity training (only 11 in our study).
}

racial attitudes. For instance, the MAKSS scales were used in six studies in our review-most showing a positive change in cognitions, attitudes, and behaviors (Abernethy, 2005; D'Andrea et al., 1991; Diaz-Lazaro \& Cohen, 2001; Guy-Walls, 2007; Murphy, Park, \& Lonsdale, 2006; Robinson \& Bradley, 1997). Further, it seems variables such as immediate response, awareness, behavior and attitude change have received the most attention in empirical research on diversity training (for exceptions see Dobbin et al., 2006; Ely, 2004a; Kellough \& Naff, 2004; Naff \& Kellough, 2003). Yet, many authors have stressed that measuring variables such as employees' perceptions of prejudice and discrimination, creativity, problem solving, and organizational flexibility are also critical to gauge the impact of diversity training (Comer \& Soliman, 1996; Cox \& Blake, 1991), and thus, should be given more attention.

To overcome limitations in measuring outcomes, we suggest that researchers focus more on developing assessment instruments based on implicit measures of attitudes and behaviors (e.g., the Implicit Association Test (IAT; Greenwald, 1998; Haines \& Sumner, 2006; The Instructor Cultural Competence Questionnaire (ICCQ); Roberson, Kulik, \& Pepper, 2002). For instance, in line with Castillo and colleagues (2007), Kulik Perry, and Bourhis (2000), and Rudman (2001), researchers can implicitly assess trainees' attitudes using semantic differential scales and response latencies (e.g., IAT). Further, a Q-sort activity to identify types of preferred behaviors or critical incident analysis of what trainees would do in a given situation (Govern, 1997; Juarez, Marvel, Brezinski, Glazner, Towbin, \& Lawton, 2006; Kulik et al., 2000; Neville \& Furlong, 1994; Roberson, et al., 2002) can be used to implicitly assess participants' behaviors. These assessment instruments are recommended because they go beyond just self-reports (the most commonly used measures in evaluating the effectiveness of diversity training), and thus, may allow generation of yet-untapped assessments of important preferences, attitudes, stereotypes, and behaviors (Haines \& Sumner, 2006). Using such implicit assessment instruments in addition to explicit (self-reports) or objective measures could advance the evaluation of diversity training. As King et al., (2010a) observed, few diversity training studies measure the presumed ultimate desired outcome of diversity training - the effect of diversity training on experiences of ethnic minorities and other groups subjected to discrimination.

Finally, another notable characteristic of diversity training research concerns the theoretical framework (or lack thereof) incorporated to guide 
the investigation. Although some nonempirical literature on diversity training has been very instrumental in offering exploratory guidance and insights on diversity troining (e.g., Paluck, 2006; Pendry et al., 2007; Wiethoff, 2004), in reality (as can be seen from our review), diversity training programs still remain somewhat atheoretical in the ways they are conducted and evaluated. We discovered that more than half $(N=106$ in our review) of the articles we reviewed were descriptive and did not follow any theoretical tradition (see Table 2). We suggest that efforts should be made to more closely connect diversity training programs with theory since theoretical frameworks have the potential to provide guidance and insights into conducting effective diversity training. In sum, research on diversity training will benefit from developing theory-based training programs.

TABLE 2

A Summary of Diversity Training Articles by Category

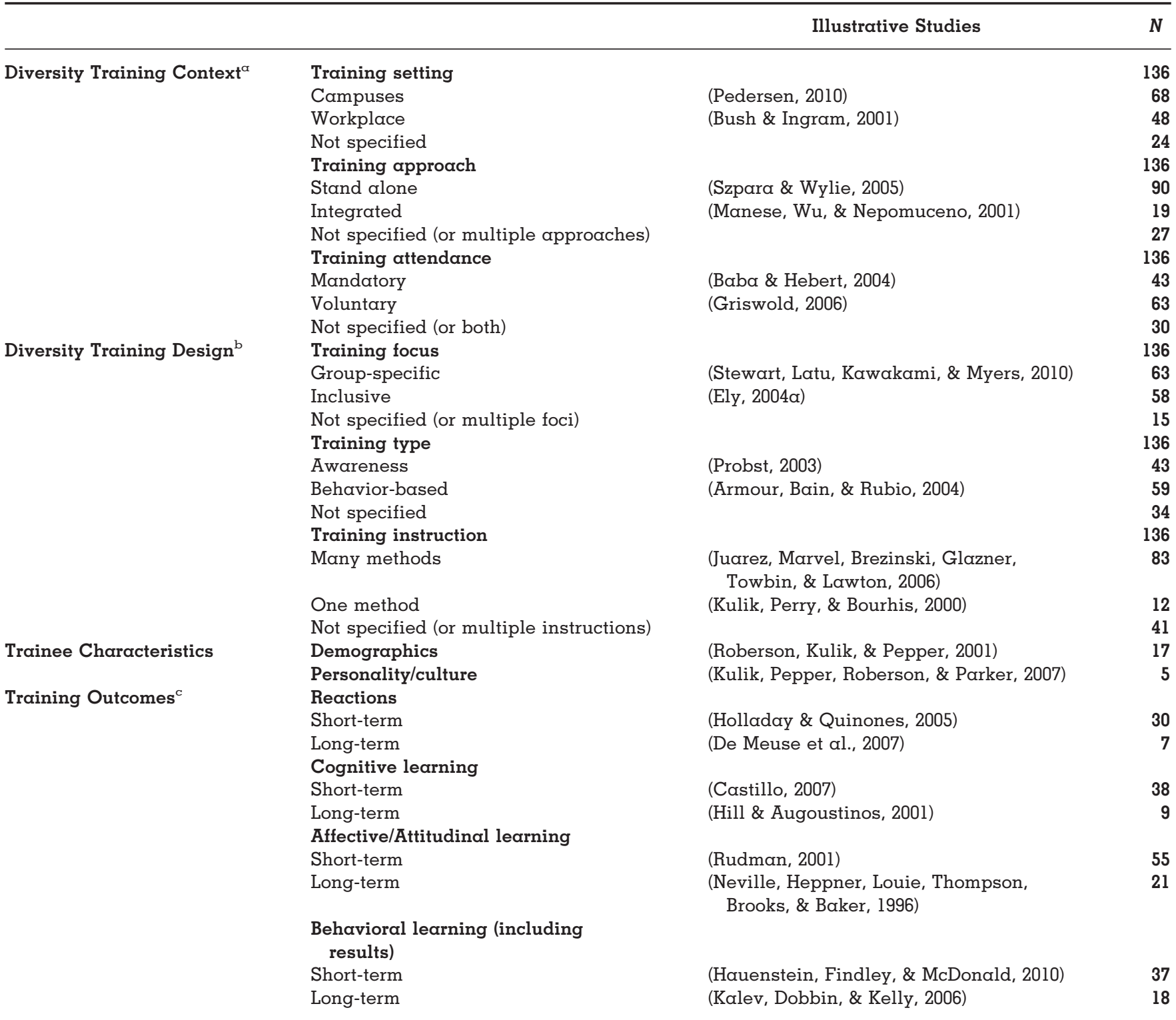

\footnotetext{
${ }^{a}$ Numbers do not add up to 178 because 42 articles were nonempirical and some articles contain multiple settings; four studies examined both diversity training on campuses and in the workplace.

b Numbers do not add up to 178 because 42 articles were nonempirical. Not specified means that a study did not provide this information or multiple diversity training programs were examined (e.g., a survey of multiple organizations with different types of diversity training).

${ }^{c}$ Numbers do not add up to 178 because some studies examined multiple outcomes, other articles were not empirical, qualitative cases, or did not provide sufficient information to determine a specific type of an outcome.
} 


\section{Diversity Training Context}

In our fromework, the second major category that we discuss is the context of the training. The setting (where the training is conducted), approach to the training, and any attendance requirements (which are typically decided by management, not instructors) that have been emphasized in the diversity training literature are considered as important context-related aspects of the training (Cocchiara, 2010; King, Gulick, \& Avery, 2010b; Kormanik \& Rajan, 2010; Thomas, Tran, \& Dawson, 2010). Table 2 summarizes the results of our review in terms of diversity training context and design, which we cover in the next section.

\section{Training Setting: Campuses Versus Workplace}

We differentiated between diversity training conducted on campuses (educational settings) as opposed to diversity training conducted in the workplace (organizational settings). Although the formats used in these settings are often rather different, we include diversity training programs in educational contexts because this is a legitimate part of management education. Diversity training on campuses has often been viewed as part of students' assimilation process to a way of thinking and hence has a primary focus on mind-set shifts (Johnson, 2008). The main goal is to prepare students for effective civic participation in the broader community by imparting multicultural awareness, knowledge, and skills. Diversity training on campuses has been represented by various educational activities such as diversity courses ( $N=35$ studies in our review), a diversity curriculum (diversity-related coursework within a curriculum, $N=7$ ), and diversity workshops (also called prejudice reduction workshops, multicultural workshops, pluralism workshops or anti-bias workshops; McCauley et al., 2000). The first two activities tend to be broader in scope, require more investment of time, and have some evaluative component (Toporek \& Pope-Davis, 2005). Although diversity courses and curricula are most common in education (cf. Avery \& Thomas, 2004), diversity workshops have been often viewed as an experiential challenge to these more traditional academic methods. Diversity workshops differ from typical instruction in a number of ways: They are usually shorter (duration of hours rather than weeks), more interactive (based on various group activities and exercises accompanied by group discussions), and emphasize affective rather than cognitive experience only (McCauley, 2000). Diversity workshops are often offered to incoming fresh- men during orientation or to students, faculty, and administrative staff during the school year.

As an example of diversity training in the educational context, a year-long study-abroad program included intercultural effectiveness, cultural immersion and coaching, and guided reflection for 32 United States college students spending a year in England (Pedersen, 2010). Comparing pre- and posttest scores on the Intercultural Development Inventory (IDI), it was found that students in a diversity training and cultural immersion course had significantly different changes in pre- and posttest scores compared to students studying abroad but not in the course, and a third control group who stayed at home. The latter two groups had no significant changes in IDI scores. The author concluded that simply sending students overseas, even for an extended period, is not sufficient to change cultural awareness, and that diversity training focused on intercultural effectiveness is necessary. Notably, the training described in this study used a variety of approaches, integrating diversity training pedagogy with cultural immersion, guided reflection, and coaching on intercultural issues.

Similarly, most diversity programs in the workplace incorporate a range of practices (e.g., training, mentoring, recruitment, management development and compensation programs) aimed at enhancing integration, creating an inclusive culture, and marketing to diverse customers (Cox \& Blake, 1991; Mor-Barak, 2005; National Urban League, 2009; Thomas, 1996). While Brewer (1999) asserted that these programs share the same objective-to achieve "full integration of members of minority social categories into the social, structural, and power relationships of an organization or institution" (Brewer, 1999: 337)—in the literature we reviewed actual training objectives are often not explicitly stated. What is consistent is that although organizational approaches to managing diversity can vary (e.g., Bendick, 2001; Kellough \& Naff, 2004; Rynes \& Rosen, 1995), diversity training is often viewed as an essential element of most diversity programs (Roberson et al., 2003). Here, the focus is specifically on training and is typically results-oriented-that is, increased skills or knowledge acquired through formal instruction (Johnson, 2008). Skill-building training educates employees on monitoring their actions and appropriate responses to specific incidents in the workplace. For instance, Hanover and Cellar (1998) examined a diversity training program where diversitymanagement related behaviors and diversity skills were key objectives. Self-reported measures of a set of 38 diversity-related behaviors and skills 
(e.g., encourages open discussion of cultural differences, openly discourages comments or jokes that perpetuate stereotypes) indicated that those taking the training engaged in such practices more often than did a control group.

Another example of workplace-based diversity training includes a program reported by Bush and Ingram (2001), who used a simulation exercise called BAFA BAFA on a sample of 122 salespeople. The study and simulation was based on uncertainty reduction theory, where individuals tried to reduce ambiguity about other parties they interacted with on a regular basis. Participants were placed in two culturally different groups: One was a competitive, trading culture, and the other was a patriarchal culture. Participants had to interpret and interact with the other (unfamiliar) culture. After the exercise, they were debriefed on cultural awareness and skill building in relation to other cultures. The authors said their most significant finding was that after taking the training, salespeople recognized that diversity training was important and required more time than they previously thought (rather than simply learning anything about diversity itself). We found that compared to training in the workplace $\left(N=48^{2}\right.$ studies in our review), diversity training in educational settings ( $N=68$ studies in our review) focused more on cognitive $\left[\chi^{2}(2, N=134)=2.012\right.$, $p<.1]$ and affective or attitudinal learning $\left[\chi^{2}(2\right.$, $N=134)=7.337, p<.01]$. This is not surprising since in education, cognitions and attitudes may be the end product the professor seeks, but in corporate training, cognitions represent only an intermediate step toward getting what employers seek, which are changes in on-the-job behaviors. Interestingly, diversity training in the workplace also emphasized more objective behaviors and results (e.g., bonuses, Ely, 2004a); however, these differences were not statistically significant. The workplace programs (particularly in the private sector) were also more likely to examine long-term effects of training than did the programs in the educational settings, $\left[\chi^{2}(2, N=134)=24.912, p<.001\right]$. We found 22 studies in the workplace as opposed to only 13 studies in educational settings (out of 136 empirical studies in our review) monitored the effects of training over time. Future research should explore the long-term implications of diversity training on students' learning and more specifically on behavioral outcomes over time (e.g., skill building in interacting effectively with different

\footnotetext{
${ }^{2}$ Note, the numbers do not add up to 178 because 42 articles were nonempirical (e.g., chapters, literature reviews, and measurement papers).
}

others). More emphasis on such behavioral outcomes in educational settings might shed light on how diversity training can have positive outcomes.

\section{Training Approach: \\ Stand-Alone Versus Integrated Diversity Training}

We differentiated diversity training in terms of either being a stand-alone initiative or integrated into a system of other diversity-related activities (see Table 2). While this theme emerged from our coding, we also found evidence supporting this distinction in other literature on diversity training (e.g., Flynn, 1998). In some companies, diversity training programs may focus on discussing legal and compliance issues or cultural topics, and be a one-time initiative (Anand \& Winters, 2008). Scholars coined this training approach as "check-offthe-box" and pointed out that many diversity programs relied on it mostly to determine how many employees have taken the training (Anand \& Winters, 2008; Curtis, Dreachslin, \& Sinioris, 2007). Yet, in other organizations, the goals of diversity training can be much broader, and training may be conducted as part of a systematic and planned organizational development effort (Bendick, 2001). Paralleling those trends in educational settings, some authors have discussed an infused curriculum approach with an emphasis on diversity across a variety of domains (supervision, coursework, research/writing), whereas others have supported a single-course approach that allows for specific time to attend to the complexity of cases that diversity naturally evokes (Murphy et al., 2006).

Researchers have argued that diversity training, by itself, would not accomplish anything very substantial (Bendick, 2001). For instance, the National Urban League (2009) reports results of a survey where 2,100 American workers ranked diversity training as 6th place in importance among 14 other diversity practices (e.g., marketing to diverse customers; retaining and recruiting diverse talent; leadership commitment, etc.). It is often assumed that a comprehensive culture change complemented by other diversity initiatives is needed to make an organization's culture inclusive and to improve a firm's diversity. When training is embedded and complemented by other diversityrelated initiatives, genuine organizational commitment and support for diversity is communicated and this should be more effective in changing attitudes, cognitions, and behaviors toward its acceptance (Curtis et al., 2007). Diversity training has thus been quickly turning into a line of work distinct from general job training programs in its em- 
phasis on building the "business case" (e.g., competitive advantage in terms of better problem solving, more organizational flexibility, attraction and retention of best talent, enhanced marketing efforts; Kellough \& Naff, 2004; Kidder, Lankau, Chrobot-Mason, Mollica, \& Friedman, 2004). Under this umbrella, diversity training has been often linked to much broader terms such as "diversity management" that emphasizes the importance of training being embedded in a corporate and managerially initiated strategy (Ivancevich \& Gilbert, 2000; Thomas, 1991).

In our review, the majority of studies have looked at stand-alone (e.g., Stewart, Latu, Kawakami, \& Myers, 2010; Szpara \& Wylie, 2005) training $\left(N=90^{3}\right)$, while there is a dearth of studies examining integrated training $(N=19)$. Yet, the relatively few studies on integrated training viewed this approach to training very positively (Bendick, 2001; Naff \& Kellough, 2003; Rynes \& Rosen, 1995). For example, Bendick (2001) compared two versions of diversity training-isolated diversity training versus diversity training complemented by other diversity initiatives-and found the latter to be more effective as perceived by the providers of diversity training in the United States. Evidence from the educational context typically comes from evaluating diversity courses conducted within diversity-infused curricula (supervision, coursework, writing/research, campuswide cultural "celebration" events, cultural immersion-all with an emphasis on diversity; e.g., Alcalde \& Walsh-Bowers, 1996; Caffrey, 2005; Klak \& Martin, 2003; Manese, Wu, \& Nepomuceno, 2001). So, the literature suggests that the impact of diversity training is related to its integration in other organizational initiatives or signals from top management that it is a priority for the organization or college and not just "window-dressing."

Some attempts have been made to go beyond testing simple comparison models to look at the effects of training within broader research models (Hanover \& Cellar, 1998; Law, 1998). For instance, a significant body of research has suggested that support for training (e.g., top management commitment to diversity, high strategic priority of diversity relative to other competing objectives, presence of a diversity manager and other responsibility structures, and the existence of a large number of other diversity-supportive policies) was a strong predictor of training success

\footnotetext{
${ }^{3}$ Note, the numbers do not add up to 178 because 42 articles were nonempirical (e.g., chapters, literature reviews, and measurement papers) and 27 studies did not provide sufficient information to determine specific training approach.
}

measures such as, for example, increases in managerial diversity (Kalev et al., 2006; Kellough \& Naff, 2004; Rynes \& Rosen, 1995). Furthermore, a consideration of training within a broader program of multiple initiatives for comprehensive culture change has been shown to be a strong predictor of perceived training success (Bendick, 2001; Hite \& McDonald, 2006; National Urban League, 2009; Rynes \& Rosen, 1995; Wentling \& Palma-Rivas, 1998). From our review, it seems clear that scholars should direct more attention to understanding the advantages of the integrated training programs and why and how they work. Research should thus consider the underlying process behind how integrated training conveys commitment and overall organizational support, and the specific ways that an organization can signal such support that are most closely related to diversity training outcomes.

\section{Training Attendance Requirements: Mandatory or Voluntary}

In our review, we distinguished between diversity training that is required for participants (mandatory) and voluntary training (see Table 2). While these themes emerged from our coding, we also found evidence supporting this distinction in the literature on diversity training (e.g., Kulik \& Roberson, 2008a). On the one hand, research has suggested that if an organization wants all of its employees to have some basic competence in training, it should be required (Johnson, 2008). According to this line of reasoning, mandatory diversity training reflects inclusion on an institutional level as it sends a message about the organization's commitment to diversity (Kellough \& Naff, 2004; Paluck, 2006; Rynes \& Rosen, 1994). Scholars supporting this argument suggest that offering diversity training on a voluntary basis may result in "preaching to the converted," missing the employees who need the training most (Ellis \& Sonnenfeld, 1994). A case of mandatory diversity training was found in Baba and Hebert's (2004) study of a postrelease program of a Department of Corrections facility in California. It was found that after the program the participants had increased awareness of racial and ethnic differences, which was opposite to the expected outcomes of the training. In contrast, other research has argued that training will be more successful when it is voluntary. This alternative view on training attendance requirements rests on the idea that diversity training programs should not be focused on remedying past discrimination (these are the goals of affirmative action), but should rather emphasize the value in 
diversity and how an organization can benefit from it (Griswold, 2006; Naff \& Kellough, 2003). Thus, attendance requirements remain an unresolved controversy in the literature on diversity training.

In our review, we found that 43 studies examined diversity training programs that were mandatory, whereas 63 studies focused on training programs that operated on a voluntary basis (see Table 2). The argument in favor of mandatory attendance has received some empirical support-mandatory management attendance was positively associated with the perceived success of diversity training (Bendick, 2001; Rynes \& Rosen, 1995). Similarly, other studies have supported the opposite argument showing that voluntary diversity training can also be beneficial (see Dobbin \& Kalev, 2007; Kaplan, 2006). For instance, Dobbin and Kalev (2007) reported an increase in proportion of female and minority employees in management positions when training was voluntary. The question thus becomes one of identifying specific conditions when voluntary training is better than mandatory and vice versa. Future research should look into this question more deeply given that it might have implications for minority representation in the workforce and likely would be welcomed by the diversity training community.

\section{Diversity Training Design}

In our framework, the next major category that we discuss is the design of diversity training. Training focus, types, and instructional characteristics have emerged from our coding and have also been emphasized in the diversity training literature as important design-related aspects of training (Bell, Connerley, \& Cocchiara, 2009; Roberson, et al., 2003; Thomas, et al., 2010).

\section{Training Focus: Group-Specific Versus Inclusive}

We further distinguished between diversity training that focuses on either group-specific topics (e.g., race, gender) or emphasizes inclusiveness across multiple groups (see Table 2). The training's focus may range from addressing group-specific differences such as race or gender to training that stresses inclusiveness across multiple groups, which is a way of embracing diversity that encompasses all employees or students, irrespective of racial, gender, or other categories (Ivancevich \& Gilbert, 2000; Roberson, et al., 2003; Stewart, Crary, \& Humberd, 2008; Thomas, 1991). Thomas (1991) suggested that having a narrow (group-specific) focus in diversity training would result in incomplete transformation of organizational culture and that expanding the discussion beyond race, ethnicity, and gender would optimize the use and contributions of all segments of a diverse workforce. The key argument for adopting such on "inclusive" focus over the "group-specific" one is that it is less likely to exacerbate intergroup tensions because it shifts attention away from "what is wrong with this outgroup" (e.g., "women need to learn to be more assertive") to "what is wrong with this organization that treats outgroups worse than ingroups?" This training essentially leaves group-specific issues behind to focus instead on the inclusiveness of the organization's culture and typically uses individual group experiences as illustrations of the general phenomenon, not as the primary subject.

In our review, we found that 63 studies focused on group-specific training, which we define as emphasizing up to two attributes (typically race and gender). One example is the training to reduce stereotyping based on race $(N=35)$, reported by Stewart et al., (2010). In their study, the focus was on the attributions underlying stereotyping; the goal of the training was to teach individuals to consider situational attributions for behaviors of outgroup members when they see behaviors consistent with negative stereotypes by these outgroup members. White participants in two experiments were trained to consider situational instead of dispositional attributions for negative stereotype-consistent behaviors performed by AfricanAmerican men. The results indicated that the training reduced automatic racial stereotyping relative to a control group who did not receive the training. Other examples of this type of diversity training in our review included diversity training focusing on culture $(N=5)$, age $(N=5)$, LGBT $(N=5)$, disability $(N=1)$, or on both gender and race $(N=12)$.

In contrast to the exemplar study above, 58 studies in our review described diversity training initiatives structured around multiple groups (e.g., race, gender, age, socioeconomic status, disability etc.) together, emphasizing what all demographic groups have in common (see for exceptions Ely, 2004a; Kracht, 1998; Sanner, 2010). For instance, some diversity training programs "are aimed at changing the corporate culture so as to ensure a workplace where employees of all backgrounds and perspectives feel welcome, and where every employee feels her or his talents are matched by opportunities to grow and contribute" (Ely, 2004a, 2004: 762). A few attempts have been made to understand more specifically how the froming of diversity training may influence participants' attitudes and other outcomes (Holladay et al., 2003; Kaplan, 2006; Kulik et al., 2000). For instance, stud- 
ies have found that a training frame using a broader (inclusive) focus of the training (e.g., race, gender, and age, etc.), as opposed to a narrow (group-specific) focus (e.g., only race) reduced the perception of backlash (Holladay et al., 2003). ${ }^{4}$

To summarize, about half of the studies we reviewed have focused on multiple attributes emphasizing the generic dynamics of multiple groups (e.g., race, gender, age, SES, disability, etc.). We think this is a good trend in diversity training proctice since this type of training sends a positive message to everyone that they are included. This positive and inclusive approach to training is likely to be better accepted by all trainees. Given these findings, it would be helpful if future research examines the mechonism by which organizations and universities can effectively communicate inclusiveness to trainees. Also, it would be useful to identify any conditions or circumstances where diversity training that focuses on only one group (group-specific focus) would be appropriate. For instance, recent work on needs assessment for diversity training (Roberson et al., 2003) has suggested that a narrowly focused training based on race only may be, in fact, beneficial when organizational goals are limited to very specific outcomes (e.g., hire more racial minorities). Other attributes such as age, disability, and LGBT should be considered in this context as well.

\section{Training Types: Awareness and Behavior-Based}

While diversity training may focus on different outcomes (e.g., cognitive, attributional, experiential, self-awareness, and behavioral), we identified two types that have been primarily discussed in the literature and have also emerged from our analysis of the articles: awareness training and skill-building or behavior-based training (e.g., Cox \& Blake, 1991; Flynn, 1998; Kulik \& Roberson, 2008b; Roberson et al., 2003). Awareness training frequently emphasizes having people share experiences with one another (Roberson et al., 2001) and focuses on promoting participants' self-awareness on diversity-related issues such as cognitive biases and heuristics that may affect the interpretation of others' behavior (Probst, 2003). For instance, Robinson and Bradley (1997) point to an emphasis on an awareness of one's own cultural assumptions, values, and biases as well as knowledge of other worldviews. Some awareness training programs also cover other-awareness, for instance, Baba and Hebert (2004) described a training pro-

\footnotetext{
${ }^{4}$ Note, no formal training was involved in this study.
}

gram that included modules on awareness of other cultures and ethnic backgrounds. Typically, the goals of this training target cognitive and affective or attitudinal learning of participants.

In contrast, behavior-based training educates participants on monitoring their own actions and giving appropriate responses to specific differences in the workplace or classroom, such as identifying and overcoming interracial communication barriers (e.g., openly discouraging racial jokes; Hanover \& Cellar, 1998). In these cases, trainees often practice communication with individuals in ethnic minorities with the assistance of a helper from the minority person's culture (Parker, Moore, \& Neimeyer, 1998). Diversity training programs can also target building skills not only in relationships with others, but also in a relationship with self (e.g., avoidance behaviors with respect to culturally different others; Armour, Bain, \& Rubio, 2004). As an example, some types of cultural sensitivity training attempt to change the degree to which an individual is able to deal with the stressful feelings of frustration, confusion, or loneliness often experienced when interacting with people of other cultures (Majumdar, 1999). Typically, the goals of this type of training include changing behaviors to effectively manage a diverse workforce and customer base (e.g., in terms of interactions with customers and other employees, conducting job interviews, and managing conflict; Cox, 1991; Hanover \& Cellar, 1998).

Behavior-based training is rarely used alone; it is usually conducted in conjunction with awareness-based training. A common assumption is that if a program targets both awareness and behaviors, it should be more effective than diversity training based on awareness only (Griffiths, 2005; National Urban League, 2009; Wentling \& PalmaRivas, 1998). However, when it comes to specific types of diversity training, such as those that address lesbian and gay topics in the workplace, a strong behavioral component can be harmful (Kaplan, 2006; Van Den Bergh, 1999). For instance, in a qualitative study of three court cases, Kaplan (2006) found that the most detrimental content (e.g., where the company lost the case) was associated with a behavior change-oriented diversity training program that challenged someone's existing belief system. This research recommends using simple statements (that do not ask trainees to accept or embrace diversity) and focus on increasing knowledge (rather than on more active and changeoriented contents) to find the correct balance and avoid unnecessary feelings of discrimination against one's beliefs. Another important assumption related to training types is that training 
should be effective when expectations and goals align (Roberson et al., 2003). For example, Armour Bain, and Rubio, (2004) indicated significant selfreported behavioral changes in response to awareness- and skill-based diversity training; participants reported fewer avoidant behaviors with students over time. However, if a program seeks to change employees' behaviors in response to awareness-based training, diversity training may not be beneficial (e.g., Roberson et al., 2002).

Emergent from our coding and in agreement with the review above, we found that studies were split into those examining awareness only $(N=43)$ and those examining both awareness and behavior training ( $N=59$; see Table 2). For example, Sanchez and Medkik (2004) measured both knowledge of social perception bias (awareness) and participants' behaviors toward individuals from other ethnic backgrounds (as rated by coworkers). The quasi-experiment evaluated effects of cultural awareness training toward 125 managers in a county government. The results showed that trainees received higher ratings of differential treatment from minority coworkers than did a control group. Postexperimental interviews led to the conclusion that differences in differential treatment were due to resentment of the trainees to the training itself, or the act of being sent to the training. This led the authors to suggest that organizations need to be careful about the desired or expected outcomes of diversity training; they may not get the outcomes they desire in the absence of a supportive management environment, especially if more is expected of the training than what it can provide.

Further, our review shows that a misalignment of expectations and goals has been rather common in diversity training programs. More specifically, while some programs sought to change employees' behaviors by practicing certain skills, others still expected changes in participants' behavior in response to awareness-based training. For instance, we found that out of the 43 awareness-only training studies, 12 still evaluated behaviors when the training initiative was not designed to develop skills and change behaviors. In contrast, 57 studies evaluating awareness and behavior-based training assessed both outcomes. As an example of a study where goals and delivery were aligned, Hauenstein, Findley, and McDonald (2010) used situational judgment tests to evaluate training that sought to improve job behaviors with respect to diversity. The training was delivered and assessed through trainees' responses to sample sets of scenarios based on an archive of complaints surrounding a workplace-based differential treatment offense. In this case, training to change behavior was done through considering past responses to critical incidents of past differential treatments. Future research should focus on the process by which training goals and training delivery can be aligned and on the implications of this for diversity-training effectiveness.

\section{Training Instruction: Many Versus One Method}

In our review, we distinguished between diversity training that uses only one instructional method versus training that employs many different methods (see Table 2). Lecture-based diversity training (Lee, 2006), training based on video materials (Chrobot-Mason, 2004; Kulik et al., 2000), or a simulation problem-solving exercise only (e.g., BAFA, Bush, \& Ingram, 2001; Flynn, 1998; Jane Elliott's "Blue-Eyes/Brown-Eyes;" Stewart, LaDuke, Bracht, Sweet, \& Gamarel, 2003) are some examples of diversity training based on only one instructional method. Other diversity training programs utilize $a$ variety of different instructional techniques, such as role playing, lectures, experiential exercises, discussion, and other learning methods of teaching. These diversity training programs are typically viewed more positively in the literature than those based on one method (e.g., see research on learning styles; Kolb, 1984; Kolb \& Kolb, 2005) and perceptual preferences (e.g., Fleming \& Mills, 1992). For instance, according to Kolb and Kolb (2005), learning requires facing and embracing differences, and most effective learning occurs when a learner "touches all the bases" and balances feeling, thinking, acting, and reflecting learning styles. This can take place in the form of various learning modalities (e.g., e-learning, learning labs, learning communities; Anand \& Winters, 2008). Similarly, Fleming and Mills (1992) encouraged the use of a variety of modal preferences in instructors' presentations. Modal preferences include aural, visual, and kinesthetic modes and are necessary to capitalize on diversity training in terms of improvements in learning outcomes.

Our coding showed that the majority of studies that we reviewed focused on diversity training based on many instructional methods $(N=83$; see Table 2). This is not surprising in light of learning research arguing that multi-instructional training (based on multiple training methods) should be more beneficial (Merriam \& Caffarella, 1999; Mezirow, 1985; Oddi, 1983; Piaget, 1966; Vann, 1996; Waddill \& Marquardt, 2003). As an example, Juarez et al.'s (2006) study reported a training program that included panel presentations, home visits, book and video discussions, relationship-centered 
interview training, simulated patient sessions based on case analysis, and other methods. There has been a dearth of studies examining the effects of diversity training based on one method $(N=12)$. While prior research tells us little about which type of instruction (one vs. many) can be successful, given the lack of studies on training using one method, future research should look into when or under what conditions a specific mode (or how many modes) of training might be most helpful. Also, research could look at each method to see what conditions it is best tailored for, or what combination of methods works best. We next turn to the characteristics of trainees themselves.

\section{Trainee Characteristics}

Another theme that emerged from our review of the diversity training literature was the characteristics of trainees themselves. Even though relatively few studies have examined this issue, the effects of diversity training programs have been linked to trainees' demographic attributes, such as race, gender, and age characteristics (e.g., Ely, 2004a; Kulik, Pepper, Roberson, \& Porker, 2007). Although trainees' race has received the most research attention in this area, findings have been highly inconclusive. For instance, some research has provided empirical support for the effects of trainees' race on training outcomes (Howe, 2001; Stewart et al., 2003), yet other research has shown trainees' race or ethnic identification had no effect (Ely, 2004a; Kulik et al., 2007; Law, 1998). Similarly, no significant effects were found for trainees' gender identity or their age on outcomes (Ely, 2004a; Howe, 2001). There has also been some interesting research that examined how the demographic composition of trainee groups may influence diversity training outcomes. Roberson and colleagues (2001) found an apparent paradox that trainees with more diversity training experience benefited from a racially homogeneous training group. They concluded it provided trainees with the security and confidence needed to develop skills. The authors suggested that the decision to use homogeneous or heterogeneous groups should depend on an assessment of trainees' diversity experience and training goals.

The effects of diversity training programs have also been examined as being conditional upon trainees' personality and cultural attributes. Participants' cognitive busyness and a need for cognition (a relatively stable curiosity disposition to engage in and enjoy effortful thinking) have received some attention in the literature (Hogan \& Mallott, 2005; Kulik et al., 2000; Roberson et al.,
2001). Participants who were cognitively busy and who had been instructed to suppress thoughts about applicant age evaluated an older applicant more negatively than participants in other experimental conditions (Kulik et al., 2000). Further, students who measured high in need for cognition had lower prejudice scores than students who measured low in need for cognition, yet this difference was the same under the condition of being told to suppress thoughts about age (Hogan \& Mallott, 2005). There has been some empirical evidence suggesting that trainees' cultural attributes may have an effect on diversity training outcomes (Holladay \& Quinones, 2005; Kulik et al., 2007). In a study of an awareness-based diversity training program, Holladay and Quinones (2005) found that trainees from more individualistic countries (e.g., Netherlands, UK, USA, and Germany) were more receptive in terms of their reactions toward diversity training than trainees from collectivistic countries (Brazil, India, and Japan). Trainees from individualistic countries further showed no preference toward a particular trainer, whereas trainees from collectivistic countries had preference toward trainers whose cultural background matched their own. Another survey-based study demonstrated how cultural competency predicted participants' attendance in an equal opportunity training program; those who had high levels of cultural competence were more likely to come to the training session (Kulik et al., 2007).

Even though the importance of considering trainee characteristics has received attention in the more general literature on training (e.g., Brown, 2001), we found only 17 studies that considered trainee characteristics and their implications for the outcomes of diversity training, thus suggesting that this area provides many opportunities for future research (see Table 2). A few studies examined the effects of diversity training programs as being conditional upon the trainees' individual characteristics (race, gender, age, culture, personality) and the composition of the training group (e.g., Ely, 2004a; Howe, 200l; Kulik et al., 2007; Law, 1998; Stewart et al., 2003). While some studies indicated that the culture of the participants' home country (e.g., individualistic or collectivistic) can be predictive of certain outcomes of diversity training (e.g., Holladay \& Quinones, 2005; Kulik et al., 2007), no conclusive evidence has been found with respect to which demographics (e.g., race, gender, etc.) were the most resistant to training. Surprisingly little research has been done on participants' age (see, for an exception, Bertolino, 2011), especially given the increasing age of the workforce, and interest in how to manage effectively across 
generations (Gravett \& Throckmorton, 2007). Further, research has shown that the diversity of trainees matters only when training goals focus on changing on-the-job behavior and trainees have prior training experience (Roberson et al., 2001), yet it is still not clear when trainees suffered the greatest backlash. Given the lack of attention to this topic and that the few studies out there have generated very interesting results, we call for more research on trainee characteristics to answer these important questions. Related to individual trainee characteristics is research on the significance of diversity based on surface level (visible) factors such as gender versus deep-level diversity based on personality and other not readily visible factors (e.g., Harrison, Price, \& Bell, 1998; Harrison, Price, Gavin, \& Florey, 2002). Knowing more about the relative effect of the two types of diversity (e.g., when personality differences matter more than racial differences) may do much to increase our understanding of the role of trainee characteristics in diversity training.

\section{Diversity Training Outcomes}

The last part of our conceptual framework is concerned with the outcomes of diversity training (see Table 2). In our analysis of the articles, we focused on trainee reactions, affective or attitudinal, cognitive, and behavioral learning outcomes in line with Kraiger et al., (1993) and Kirkpatrick and Kirkpatrick (2006) and consistent with recent research by Brown (2005), Dierdorff (2010), and Holladay and Quinones (2008). We examined both short- and long-term effects of training. Short-term evaluation (72 studies in our review) of diversity training typically occurs at the very end of the training. For instance, participants complete the scales at the end of the semester (in the case where a diversity course is being evaluated) after completion of their final exam (Murphy et al., 2006). Long-term evaluation (35 studies in our review) is typically lagged and occurs after some time (range $=4$ weeks to 4 years, $\mathrm{x}=52.3$ weeks, $S D=51.1$ in our review). We also discuss the measurement issues associated with specific outcomes.

Reactions typically include trainees' perceptions of the trainer's competence, credibility, and experience as well as the usefulness of training overall (Holladay \& Quinones, 2005; Rynes \& Rosen, 1995). Some studies also examined reactions in terms of expected backlash (trainees' beliefs that the training will make things worse for minority members by threatening the majority), organizational message (trainees' perceptions of how the training program will impact the organization), and likelihood of transfer (trainees' perceptions that the content presented in the course will increase their ability to interact with different others; Holladay et al., 2003; Holladay \& Quinones, 2008). For example, in the Holladay and Quinones (2008) study, a 20-item scale was used to assess participants' backlash against the training and reactions toward the trainer in a sample of 191 undergraduate psychology students. Holladay and Quinones found that when the training focused on similarities among individuals, trainees expected fewer instances of backlash and were more effective at resolving conflicts than when the training focused on differences among individuals. Also, trainee reactions were found to be a mediating factor between training focus and affectively based learning criteria.

Cognitive learning refers to the extent to which trainees acquire knowledge. Different tests have been designed to assess participants' knowledge and learning of the facts and principles of diversity sensitivity presented during the training. For instance, the knowledge subscale of the MCI has been used in studies examining the impact of training on multicultural counseling competencies of school psychologists and clinical students (e.g., Castillo, 2007; Williams, 2005). This scale assesses a counselor's breadth and grasp of the knowledge base of multicultural counseling research, cultural information, and treatment strategies (Sodowsky, Taffe, Gutkin, \& Wise, 1994). Another measure that has been frequently used to measure participants' learning is the Multicultural Awareness Questionnaire (Law, 1998). This test assesses participants' knowledge about cultural diversity issues by calculating the total number of correct responses.

Affective learning captures changes in attitudes toward diversity as well as changes in trainees' self-efficacy (trainees' beliefs in their capacity to perform). Typical measures of attitudinal outcomes considered in the studies were self-assessments of attitudes toward ethnic groups (e.g., Europeans, Mexican-American, African-American; Tran, Young, \& Di Lella, 1994), gender, social class, sexual orientation, language, ability and other differences (e.g., the Beliefs About Diversity scale; Middleton, 2002), or intercultural issues ((Klak \& Martin, 2003). Another example of an attitudinal measure that has been used in the past (e.g., Stella, Forlin, \& Lan, 2007) includes the ATIES (Wilczenski, 1992). This measure assesses participants' attitudes toward including students in mainstream schools who have social, physical, academic, and behavioral learning needs. Unlike explicit measures based on self-assessments of attitudes, semantic differential scales have been used to assess attitudes implicitly (Cleveland, 1988). For 
instance, participants' stereotypes toward older workers were measured with these items: 1 = active and $7=$ passive, $l=$ productive and $7=$ unproductive, and so on (Kulik et al., 2000).

Behavioral learning concerns the development of trainees' skills. Here research describes not only explicitly (via self-reports) or implicitly identified skills, but also objective behaviors and results. The most frequently used self-reports are based on assessments of trainees' abilities to resolve conflict (Holladay \& Quinones, 2008) or measure self-perceptions of behaviors believed to contribute to effective diversity management in the workplace (e.g., "openly discourages comments or jokes that perpetuate stereotypes or prejudice," Honover \& Cellar, 1998). An example of an implicit measure includes a Q-sort activity to identify the type of people with whom participants felt least comfortable and then designate levels of intensity of participants' feelings. This activity typically involves placing adjectives on a continuum from "the most accurate description of how I feel about this person" to "the least accurate description of how I feel about this person" (Juarez et al., 2006). Finally, examples of objective measures of behaviors and results include content-analyzed behaviors or situational judgment tests (Hauenstein et al., 2010; Roberson et al., 2001; Stroup, 1998), performance evaluation of a trainee by a manager or trained observers (Juarez et al., 2006; Sanchez \& Medkik, 2004), increases in performance (sales productivity, customer satisfaction, etc.; Ely, 2004a) or promotions and representation of women and minorities in leadership positions (Kalev et al., 2006; Naff \& Kellough, 2003).

In our review of the studies that reported information on reactions, we found that 30 examined short-term reactions (e.g., Holladay \& Quinones, 2005,2008 ) and only 7 studies evaluated long-term reactions (e.g., De Meuse et al., 2007) to training (see Table 2). This is somewhat surprising considering the fact that trainee reactions have been the primary means by which organizations evaluate training programs (Sitzmann, 2008). Turning to cognitive learning, we found that 38 studies examined short-term effects of training, whereas only 9 studies looked at the long-term effects of training. For an example of a study considering long-term effects, Hill and Augoustinos' (2001) 3-month follow-up data of a field experiment of 62 trainees found evidence that the effects of diversity training can persist over the long term. This study examined the impact of a cross-cultural awareness program (a 3-day antiracist educational program that adopts a workshop format) on stereotype change and prejudice reduction toward Aboriginal Austra- lians. A significant increase in participants' level of knowledge of Aboriginal cultures persisted in the long term. With respect to affective learning, we found that short-term attitudes (e.g., Rudman, 2001) were the most studied outcomes of diversity training $(N=55)$, and 21 studies reported long-term effects for affective or attitudinal learning. There was some evidence suggesting that the changes in attitudinal learning could persist over 6 months (Thomas \& Cohn, 2006) and deteriorate after 1 year (Hogan \& Mallott, 2005; Neville, Heppner, Louie, Thompson, Brooks, \& Baker, 1996). Turning to behavioral learning, we found that 37 studies reported short-term effects (e.g., Hauenstein et al., 2010), whereas 18 studies focused on long-term behavioral consequences of diversity training (e.g., Kalev et al., 2006; Roberson et al., 2009). Behavioral learning was primarily measured explicitly by way of self-reports $(N=36)$, with a relatively small number of studies employing implicit $(N=7)$ or objective measures of change $(N=10)$. This is one area where future research can shed light on how diversity training can transfer into the outcomes most critical for organizations and campuses.

\section{CONCLUSIONS}

Our review suggests that while diversity training can indeed be impactful in organizations, some areas where diversity training would seem to have the greatest impact and promise (e.g., an integrated approach to diversity training) have been relatively ignored. On the other hand, our review reveals that the content and effectiveness of some diversity training programs can be questionable (e.g., a stand-alone approach, focusing on specific groups, e.g., race, using one method of instruction, e.g., lecture). Yet, the increasing demand for diversity training due to major societal and organizational trends (e.g., changing workforce demographics, firms' globalization, and continuing legal challenges) calls for better understanding of what type of programs can make a difference in how we research and teach about diversity. The purpose of this review, therefore, was to understand what has been done and what needs to be done with respect to diversity training. To guide the efforts in developing diversity training programs, we have proposed a framework that classifies the topics related to diversity training, points to gaps in the literature, and provides suggestions for future research. We have also included exemplars in each section, so if readers feel this is the design they desire, they have a ready example and citations of studies investigating this design along with characteristics of a particular design element. 
Overall, in terms of context, diversity training has been frequently found in both educational and workplace settings across a variety of industries, demonstrating its pervasiveness in society. Our review further shows that the training approach described as integrated (training is conducted as part of a systematic and planned organizational development effort) has been less prevalent, yet viewed more favorably in the literature than standalone training (e.g., Alcalde \& Walsh-Bowers, 1996; Bendick, 2001; Caffrey, 2005; Klak \& Martin, 2003; Rynes \& Rosen, 1995). Approximately equal attention has been given to both voluntary and mandatory diversity training. Yet, the appropriate use of voluntary or mandatory requirements under different conditions remains unknown. Further, we found a myriad of different forms, shapes, and combinations of diversity training in terms of its design elements. While programs with an inclusive focus (focusing together on the experiences of African-Americans, women, gay, lesbian bisexual, and transgender, GLBT persons with disabilities, etc.) were less prevalent, authors viewed them more positively in the literature than they did training that focuses on only one group (e.g., race, as our earlier example demonstrates). Also, diversity training programs that were primarily designed to increase both diversity awareness and skills and those that employed many instructional methods (e.g., lectures, exercises, group activities and discussions, etc.) were most common. Demographic, personality, and cultural characteristics of the trainees have received some attention in the literature, yet more often than not these aspects have been ignored. In terms of training outcomes, researchers predominantly focused on short-term effects as opposed to long-term effects with the majority of outcomes involving attitudinal learning.

These findings open the door to future research directions. First, given the lack of attention to integrated and inclusive diversity training, we call for more research to understand why the few studies that did look at integrated contexts and inclusive designs of diversity training were promising. Since integrated training has been linked to increased commitment of top management, research should strive to understand the mechanism behind such commitment as well as ways of communicating inclusiveness to trainees. Another lightly studied, yet very important area of research, was participants' characteristics and how they relate to the training itself, to the trainer, and to fellow participants. Knowing more about participants' and trainers' characteristics will inform issues such as selection of individuals to the training and under- standing backlash to training. Finally, the predominance of outcomes studied included short-term attitudes, yet it would seem critical to deepen our understanding of changes in long-term behaviors and cognitions resulting from diversity training. These outcomes are likely to have the strongest ties to the ultimate purpose of diversity training to the experiences that minorities feel at work or in school over time. Overall, our review shows that there are vast opportunities for contributions to the field of diversity training.

\section{Limitations and Future Research}

In our narrative review, we have examined both qualitative and quantitative studies so that we do not bias selection by methods used in studies on diversity training and we retain as many studies as possible. Thus, our conclusions are about strengths and weaknesses of the current literature that can allow us to understand where the field is regarding this type of research. A limitation of this study, then, is that we can make no claims about the relative effectiveness of different types of diversity programs, as there are differences in what has been emphasized and how training programs were studied. Yet, we do contribute to what we know about diversity training by making assessments of what has been done and by identifying the relevant research issues to date with respect to all important characteristics (e.g., context, training design, outcomes, participants, and research characteristics). The findings from our narrative review thus can guide future research on diversity training, making meta-analysis using the framework we developed possible as a next step.

\section{Practical Implications}

Our findings with respect to the design characteristics of training have implications for teaching. For example, the literature we reviewed shows that diversity training programs with a specific focus that emphasize learning about one particular demographic group at a time may be somewhat problematic, possibly because such an approach sharpens differences between participants and make reasons for inequitable treatment and discrimination more salient to participants. Such priming effects brought on by training may cause a backlash among participants in demographic majorities who may feel they are being held indirectly responsible for past histories of discrimination or other inequities. In contrast, training that focuses on a more general, positive, and inclusive approach may 
be better received by all participants. More specifically, case studies where diverse workplaces have been very successfully managed, such as Cirque du Soliel (Delong \& Vijayaraghavan, 2002), Google, The Metropolitan Opera, and Cityside Financial Services (Ely, 2004b) can be included in a course syllabus or discussed as part of diversity training in the workplace. Unlike programs focusing on specific groups, this type of approach may provide the illustrative examples of companies that are very diverse but also extremely successful, where the inclusiveness of different groups is a key competitive advantage.

Our study has shown that much work remains to fill the gaps in research on diversity training. In endeavoring to meet our objectives, we have described what research has focused upon, where attention is needed, and important aspects of the design characteristics that have been emphasized in the literature. In terms of overall shortcomings of the literature, we find that diversity research has been widely criticized for the lack of guiding theory (Paluck, 2006; Smith, Constantine, Dunn, Dinehart, \& Montoya, 2006) and a lack of agreement about the measurement of training effects. Even with those deficiencies and others that we have pointed out (e.g., paucity of outcome statistics), we conclude on an optimistic note by reiterating that the articles we reviewed indicate the importance and interest in diversity training and lay some groundwork for advancing our knowledge about this subject. In synthesizing what has been learned to date about diversity training, we hope that our study will guide future research that will, ultimately, lead to its more effective use.

\section{REFERENCES}

Abbott, R. K. 2008. Creating a culture of health: A value-driven strategy for organizational success. Journal of Compensation and Benefits, 24: 28-33.

Abernethy, A. D. 2005. Increasing the cultural proficiency of clinical managers. Journal of Multicultural Counseling and Development, 33: 81-93.

Alcalde, J., \& Walsh-Bowers, R. 1996. Community psychology values and the culture of graduate training: A self-study. American Journal of Community Psychology, 24: 389-4ll.

Alderfer, C. P. 1992. Changing race relations embedded in organizations: Report on a long-term project with the XYZ corporation. In S. E. Jackson, (Ed.), Diversity in the workplace: Human resource initiatives: 138-166. New York: Guilford Publications.

Allport, G. 1954. The nature of prejudice. Cambridge, MA: Addison-Wesley.
Anand, R., \& Winters, M. 2008. A retrospective view of corporate diversity training from 1964 to the present. Academy of Management Learning and Education, 7: 356-372.

Armour, M. P., Bain, B., \& Rubio, R. 2004. Special section: Field education in social work. An evaluation study of diversity training for field instructors: A collaborative approach to enhancing cultural competence. Journal of Social Work Education, 40: 27-38.

Asendorpf, J. B., Banse, R., \& Mücke, D. 2002. Double dissociation between implicit and explicit personality self-concept: The case of shy behavior. Journal of Personality and Social Psychology, 83: 380-393.

Astin, A. W. 1993. Diversity and multiculturalism on the campus: How are students affected? Change, 25: 44-49.

Avery, D. R., \& Thomas, K. M. 2004. Blending content and contact: The role of diversity curriculum and campus heterogeneity in fostering diversity management competency. Academy of Management Learning and Education, 3: 380-396.

Baba, Y., \& Hebert, C. 2004. The effects of participation in a cultural awareness program on jail inmates. Journal of Ethnic and Cultural Diversity in Social Work, 13: 91-113.

Baldwin, T. T., \& Ford, J. K. 1988. Transfer of training: A review and direction for future research. Personnel Psychology, 41: 63-105.

Bell, M. P., Connerley, M. L., \& Cocchiara, F. K. 2009. The case for mandatory diversity education. Academy of Management Learning and Education, 8: 597-609.

Bendick, M., Egan, M. L., \& Lofhjelm, S. 2001. Workplace diversity training: From anti-discriminatory compliance to organizational development. Human Resource Planning, 24: 10-25.

Bennett, M. 1993. Towards ethnorelativism: A developmental model of intercultural sensitivity. In R. Paige, ed., Education for the intercultural experience. Yarmouth, ME: Intercultural Press.

Bertolino, M., Truxillo, D. M., \& Fraccaroli, F. 2011. Age as moderator of the relationship of proactive personality with training motivation, perceived career development from training, and training behavioral intentions. Journal of Organizational Behavior, 32: 248-263.

Blume, B. D., Ford, J. K., Baldwin, T. T., \& Huang, J. L. 2010. Transfer of training: A meta-analytic review. Journal of Management, 36: 1065-1105.

Brewer, M. B., Hippel, W. V., \& Gooden, M. P. 1999. Diversity and organizational identity: The problem of entree after entry. In D. A. Prentice \& D. T. Miller, eds., Cultural divides: Understanding and overcoming group conflict: 337-363. New York: Sage.

Brown, K. G. 2001. Using computers to deliver training: Which employees learn and why? Personnel Psychology, 54: 27l296.

Brown, K. G. 2005. An examination of the structure and nomological network of trainee reactions: A closer look at "smile sheets." Journal of Applied Psychology, 90: 991-1001.

Bush, V., \& Ingram, T. 2001. Building and assessing cultural diversity skills: Implications for sales training. Industrial Marketing Management, 30: 65-76.

Caffrey, R. A., Neander, W., Markle, D., \& Stewart, B. 2005. Improving the cultural competence of nursing students: Results of integrating cultural content in the curriculum and 
an international immersion experience. Journal of Nursing Education, 44: 234-240.

Castillo, L. G., Brossart, D. F., Reyes, C. J., Conoley, C. W., \& Phoummarath, M. J. 2007. The influence of multicultural training on perceived multicultural counseling competencies and implicit racial prejudice. Journal of Multicultural Counseling and Development, 35: 243-254.

Chrobot-Mason, D. 2004. Managing racial differences: The role of majority managers' ethnic identity development on minority employee perceptions of support. Group and Organization Management, 29: 5-31.

Cleveland, J. N., Festa, R. M., \& Montgomery, L. 1988. Applicant pool composition and job perceptions: Impact of decisions regarding an older applicant. Journal of Vocational Behavior, 32: 112-125.

Cocchiara, F. K., Connerley, M. L., \& Bell, M. P. 2010. "A GEM" for increasing the effectiveness of diversity training. Human Resource Management, 49: 1089-1106.

Combs, G. M., \& Luthans, F. 2007. Diversity training: Analysis of the impact of self-efficacy. Human Resource Development Quarterly, 18: 91-120.

Comer, D., \& Soliman, C. 1996. Organizational efforts to manage diversity: Do they really work? Journal of Managerial ISsues, 8: 470-483.

Cox, T. 1991. The multicultural organization. Academy of Management Review, 5: 34-47.

Cox, T., \& Blake, S. 1991. Managing cultural diversity: Implications for organizational competitiveness. Academy of Management Executive, 5: 45-56.

Curtis, E. F., Dreachslin, J. L., \& Sinioris, M. 2007. Diversity and cultural competence training in health care organizations: Hallmarks of success. Health Care Management Review, 26: 255-262.

D'Andrea, M., Daniels, J., \& Heck, R. 1991. Evaluating the impact of multicultural counseling training. Journal of Counseling and Development, 70: 143-150.

De Meuse, K. P., Hostager, T. J., \& O'Neill, K. S. 2007. A longitudinal evaluation of senior managers' perceptions and attitudes of a workplace diversity training program. Human resource planning, 30(2): 38-46.

Delong, T., \& Vijayaraghavan, V. 2002. Cirque du Soleil, Harvard business Case: 9-403-006. Boston: Harvard Business Publishing.

Diaz-Lazaro, C., \& Cohen, B. B. 2001. Cross-cultural contact in counseling training. Journal of Multicultural Counseling and Development, 29: 41-56.

Dierdorff, E. C., Surface, E. A., \& Brown, K. G. 2010. Frame-ofreference training effectiveness: Effects of goal orientation and self-efficacy on affective, cognitive, skill-based, and transfer outcomes. Journal of Applied Psychology, 95: 11811191.

Dobbin, F., \& Kalev, A. 2007. Kicking and screaming: Commitment and resistance in organizational diversity programs. Paper Presented at the American Psychological Association National Conference, San Francisco, CA.

EEOC Reports. 2011. In EEOC reports job bias charges hit record high in fiscal year 2010. Retrieved May 5, 2011, from www. diversity-executive.com/article.php?article $=1057$

Ellis, K., \& Sonnenfeld, J. 1994. Diverse approaches to managing diversity? Human Resource Management, 33: 79-109.
Ely, R. J. 2004a. A field study of group diversity, participation in diversity education programs, and performance. Journal of Organizational Behavior, 25: 755-780.

Ely, R. J. 2004b. Managing diversity at cityside financial services, Harvard business case: 405-047. Boston: Harvard Business Publishing.

Fleming, N. D., \& Mills, C. 1992. Not another inventory, rather a catalyst for reflection. Improve the Academy, 11: 137-145.

Flynn, G. 1998. The harsh reality of diversity programs. Workforce, 77: 26-30.

Gaertner, S. L., Dovidio, J. F., Rust, M. C., Nier, J. A., Banker, B. S., Ward, C. M., et al. 1999. Reducing intergroup bias: Elements of intergroup cooperation. Journal of Personality and Social Psychology, 76: 388-402.

Goldstein, I. L., \& Ford, J. K. 2002. Training in organizations: Needs assessment, development, and evaluation. Mason, $\mathrm{OH}$ : Cengage/Wadsworth.

Govern, D. 1997. The effect of diversity awareness training on oral presentation ratings. Dissertation Abstracts International, 58: 5681.

Gravett, L., \& Throckmorton, R. 2007. Bridging the generation gap: How to get radio babies, boomers, Gen Xers, and Gen Yers to work together and achieve more. Franklin Lakes, NJ: Career Press.

Greenwald, A. G., McGhee, D. E., \& Schwartz, J. L. 1998. Measuring individual differences in implicit cognition: The implicit association test. Journal of Personality and Social Psychology, 74: 1464-1480.

Griffiths, J. 2005. Awareness training needs practical follow-up work. People Management, 11: 17.

Griswold, K., Kernan, J. B., Servoss, T. J., Saad, F. G., Wagner, C. M., \& Zayas, L. E. 2006. Refugees and medical student training: Results of a programme in primary care. Medical Education, 40: 697-703.

Guy-Walls, P. 2007. Exploring cultural competence practice in undergraduate social work education. Education, 127: 569580.

Haines, E. L., \& Sumner, K. E. 2006. Implicit measurement of attitudes, stereotypes, and self-concepts in organizations: Teaching old dogmas new tricks. Organizational Research Methods, 9: 536-553.

Hanover, J., \& Cellar, D. 1998. Environmental factors and the effectiveness of workforce diversity training. Human Resource Development Quarterly, 9: 105-124.

Harrison, D. A., Price, K. H., \& Bell, M. P. 1998. Beyond relational demography: Time and the effects of surface- and deeplevel diversity on work group cohesion. Academy of Management Journal, 41: 96-107.

Harrison, D. A., Price, K. H., Gavin, J. H., \& Florey, A. T. 2002. Time, teams, and task performance: Changing effects of surface- and deep-level diversity on group functioning. Academy of Management Journal, 45: 1029-1045.

Hauenstein, N. M. A., Findley, R. A., \& McDonald, D. P. 2010. Using situational judgment tests to assess training effectiveness: Lessons learned evaluating military equal opportunity advisor trainees. Military Psychology, 22: 262-281.

Hill, M. E., \& Augoustinos, M. 2001. Stereotype change and prejudice reduction: Short- and long-term evaluation of a crosscultural awareness programme. Journal of Community and Applied Social Psychology, 11: 243-262. 
Hite, L. M., \& McDonald, K. S. 2006. Diversity training pitfalls and possibilities: An exploration of small and mid-size US organizations. Human Resource Development International, 9: 365-377.

Hogan, D. E., \& Mallott, M. 2005. Changing racial prejudice through diversity education. Journal of College Student Development, 46: 115-125.

Holladay, C. L., \& Quinones, M. A. 2005. Reactions to diversity training: An international comparison. Human Resource Development Quarterly, 16: 529-545.

Holladay, C. L., \& Quinones, M. A. 2008. The influence of training focus and trainer characteristics on diversity training effectiveness. Academy of Management Learning and Education, 7: 343-354.

Holladay, C. L., Knight, J. L., Paige, D. L., \& Quinones, M. A. 2003. The influence of framing on attitudes toward diversity training. Human Resource Development Quarterly, 14: 245263.

Howe, S. 2001. An investigation of the diversity sensitivity training program: What is the impact of participation?. Dissertation, University of Georgia, Athens, GA.

Ivancevich, J. M., \& Gilbert, J. A. 2000. Diversity management: Time for a new approach. Public Personnel Management, 29: 75-92.

Jackson, S. E., Joshi, A., \& Erhardt, N. L. 2003. Recent research on teams and organizational diversity: SWOT analysis and implications. Journal of Management, 29: 801-830.

Johnson, C. D. 2008. It's more than the five to do's: Insights on diversity education and training from Roosevelt Thomas, a pioneer and thought leader in the field. Academy of Management Learning and Education, 7: 406-417.

Juarez, J. A., Marvel, K., Brezinski, K. L., Glazner, C., Towbin, M. M., \& Lawton, S. 2006. Bridging the gap: A curriculum to teach residents cultural humility. Residency Education, 38: 97-102.

Kalev, A., Dobbin, F., \& Kelly, E. 2006. Best practices or best guesses? Assessing the efficacy of corporate affirmative action and diversity policies. American Sociological Review, 71: 589-617.

Kaplan, D. M. 2006. Can diversity training discriminate? Backlash to lesbian, gay, and bisexual diversity initiatives. Employee Responsibilities and Rights Journal, 18: 61-72.

Kellough, J. E., \& Naff, K. C. 2004. Responding to a wake-up call: An examination of federal agency diversity management programs. Administration and Society, 36: 62-90.

Kidder, D. L., Lankau, M. J., Chrobot-Mason, D., Mollica, K. A., \& Friedman, R. A. 2004. Backlash toward diversity initiatives: Examining the impact of diversity program justification, personal, and group outcomes. International Journal of Conflict Management, 15: 77-102.

King, E. B., Dawson, J. F., Kravitz, D. A., \& Gulick, L. M. V. 2010a. A multilevel study of the relationships between diversity training, ethnic discrimination and satisfaction in organizations. Journal of Organizational Behavior, 33: 5-20.

King, E. B., Gulick, L. M. V., \& Avery, D. R. 2010b. The divide between diversity training and diversity education: Integrating best practices. Journal of Management Education, 34: 891-906.
Kirkpatrick, D. L., \& Kirkpatrick, J. D. 2006. Evaluating training programs: The four levels. (3rd ed.). San Francisco, CA: Berrett-Koehler.

Klak, T., \& Martin, P. 2003. Do university-sponsored international cultural events help students to appreciate "difference"? International Journal of Intercultural Relations, 27: 445-465.

Kolb, A. Y., \& Kolb, D. A. 2005. Learning styles and learning spaces: Enhancing experiential learning in higher education. Academy of Management Learning and Education, 4: 193-212.

Kolb, D. A. 1984. Experiential learning: Experience as the source of learning and development. Englewood Cliffs: Prentice Hall.

Konnert, C., Dobson, K. S., \& Watt, A. 2009. Geropsychology training in Canada: A survey of doctoral and internship programs. Canadian Psychology, 50: 255-260.

Kormanik, M. B., \& Rajan, H. C. 2010. Implications for diversity in the HRD curriculum drawn from current organizational practices on addressing workplace diversity in management training. Advances in Developing Human Resources, 12: 367-384.

Kracht, D. 1998. Diversity training among manufacturing companies: Reaction and learning in a for-profit and not-forprofit work environment. Unpublished Dissertation, University of Sarasota, Sarasota, FL.

Kraiger, K., Ford, J. K., \& Salas, E. 1993. Application of cognitive, skill-based, and affective theories of learning outcomes to new methods of training evaluation. Journal of Applied Psychology, 78: 311-328.

Kulik, C. T., \& Roberson, L. 2008a. Common goals and golden opportunities: Evaluations of diversity education in academic and organizational settings. Academy of Management Learning and Education, 7: 309-331.

Kulik, C. T., \& Roberson, L. 2008b. Diversity initiative effectiveness: What organizations can (and cannot) expect from diversity recruitment, diversity training, and formal mentoring programs. In A. Brief, (Ed.), Diversity at work: 265-317. London, UK: Cambridge Press.

Kulik, C. T., Perry, E., \& Bourhis, A. 2000. Ironic evaluation processes: Effects on thought suppression on evaluations of older job applicants. Journal of Organizational Behavior, 21: 689-711.

Kulik, C. T., Pepper, M. B., Roberson, L., \& Parker, S. K. 2007. The rich get richer: Predicting participation in voluntary diversity training. Journal of Organizational Behavior, 28: 753769.

Law, D. Y. 1998. An evaluation of a cultural diversity training program. Dissertation, Auburn University, Auburn, AL.

Lee, C. A., Anderson, M. A., \& Hill, P. D. 2006. Cultural sensitivity education for nurses: A pilot study. Journal of Continuing Education in Nursing, 37: 137-141.

Majumdar, B., Keystone, J. S., \& Cuttress, L. A. 1999. Cultural sensitivity training among foreign medical graduates. Medical Education, 33: 177-184.

Manese, J. E., Wu, J. T., \& Nepomuceno, C. A. 2001. The effect of training on multicultural counseling competencies: An exploratory study over a ten-year period. Journal of Multicultural Counseling and Development, 29: 31-40. 
McCauley, C., Wright, M., \& Harris, M. 2000. Diversity workshops on campus: A survey of current practice at U.S. colleges and universities. College Student Journal, 34: 100-115.

McConahay, J. B., Hardee, B. B., \& Batts, V. 1981. Has racism declined in America? Journal of Conflict Resolution, 25: 563-579.

Merriam, S. B., \& Caffarella, R. S. 1999. Learning in adulthood (2nd ed.). San Francisco: Jossey-Bass.

Mezirow, J. 1985. Concept and action in adult education. Adult Education Quarterly, 35: 142-151.

Middleton, D. R. 2002. The challenge of human diversity: Mirrors, bridges, and chasms (2nd ed.). Long Grove, IL: Waveland Press.

Mor-Barak, M. 2005. Managing diversity: Toward a globally inclusive workplace. Thousand Oaks, CA: Sage Publications.

Murphy, M., Park, J., \& Lonsdale, N. 2006. Marriage and family therapy students' change in multicultural counseling competencies after a diversity course. Contemporary Family Therapy: An International Journal, 28: 303-31l.

Naff, K., \& Kellough, E. 2003. Ensuring employment equity: Are federal diversity programs making a difference? International Journal of Public Administration, 26: 1307-1336.

National Urban League. 2009. Diversity practices that work: The American worker speaks II, Vol. 2011. National Urban League.

Neville, H. A., Heppner, M. J., Louie, C. E., Thompson, C. E., Brooks, L., \& Baker, C. E. 1996. The impact of multicultural training on white racial identity attitudes and therapy competencies. Professional Psychology: Research and Practice, 27: 83-89.

Neville, H., \& Furlong, M. 1994. The impact of participation in a cultural awareness program on the racial attitudes and social behaviors of first-year college students. Journal of College Student Development, 35: 371-377.

Noe, R. A. 2010. Employee training and development. New York: McGraw-Hill/Irwin.

Oddi, L. 1983. The lecture: An update on research. Adult Education Quarterly, 33: 222-229.

Orne, M. T. 1962. On the social psychology of the psychological experiment: With particular reference to demand characteristics and their implications. American Psychologist, 17: 776-783.

Paluck, E. L. 2006. Diversity training and intergroup contact: A call to action research. Journal of Social Issues, 62: 577-595.

Paluck, E. L., \& Green, D. P. 2009. Prejudice reduction: What works? A review and assessment of research and practice. Annual Review of Psychology, 60: 339-367.

Parker, W. M., Moore, M. A., \& Neimeyer, G. J. 1998. Altering white racial identity and interracial comfort through multicultural training. Journal of Counseling and Development, 76: 302-310.

Pascarella, E. T., Edison, M., Nora, A., Hagedorn, L. S., \& Terenzini, P. T. 1996. Influences on students' openness to diversity and challenge in the first year of college. Journal of Higher Education, 67: 174-195.

Pedersen, P. J. 2010. Assessing intercultural effectiveness outcomes in a year-long study abroad program. International Journal of Intercultural Relations, 34: 70-80.
Pendry, L. F., Driscoll, D. M., \& Field, C. T. 2007. Diversity training: Putting theory into practice. Journal of Occupational and Organizational Psychology, 80: 227-250.

Pettigrew, T. F. 1998. Intergroup contact theory. Annual Review of Psychology, 49: 65-85.

Piaget, J. 1966. Psychology of intelligence. Totowa, NJ: Littlefield, Adams.

Posthuma, R. A., Morgeson, F. P., \& Campion, M. A. 2002. Beyond employment interview validity: A comprehensive narrative review of recent research and trends over time. Personnel Psychology, 55: 1-81.

Probst, T. M. 2003. Changing attitudes over time: Assessing the effectiveness of a workplace diversity course. Teaching of Psychology, 30: 236-239.

Roberson, L., Kulik, C. T., \& Pepper, M. B. 2001. Designing effective diversity training: Influence of group composition and trainee experience. Journal of Organizational Behavior, 22: 871-885.

Roberson, L., Kulik, C. T., \& Pepper, M. B. 2002. Assessing instructor cultural competence in the classroom: An instrument and a development process. Journal of Management Education, 26: 40-55.

Roberson, L., Kulik, C. T., \& Pepper, M. B. 2003. Using needs assessment to resolve controversies in diversity training design. Group and Organization Management, 28: 148-174.

Roberson, L., Kulik, C. T., \& Pepper, M. B. 2009. Individual and environmental factors influencing the use of transfer strategies after diversity training. Group and Organization Management, 34: 67-89.

Robinson, B., \& Bradley, L. J. 1997. Multicultural training for undergraduates: Developing knowledge and awareness. Journal of Multicultural Counseling and Development, 25: 281-289.

Rosenberg, M. J. 1969. The conditions and consequences of evaluation apprehension. In R. Rosenthal \& R. L. Rosnow, (Eds.), Artifacts and behavioral research: 279-349. New York: Academic Press.

Rossett, A., \& Bickham, T. 1994. Diversity training: Hope, faith and cynicism. Training, 31: 40-46.

Rudman, L. A., Ashmore, R. D., \& Gary, M. L. 2001. "Unlearning" automatic biases: The malleability of implicit prejudice and stereotypes. Journal of Personality and Social Psychology, 81: 856-868.

Rynes, S., \& Rosen, B. 1994. What makes diversity programs work? HR Magazine, 39: 67-68.

Rynes, S., \& Rosen, B. 1995. A field survey of factors affecting the adoption and perceived success of diversity training. Personnel Psychology, 48: 247-270.

Sanchez, J. I., \& Medkik, N. 2004. The effects of diversity awareness training on differential treatment. Group and Organization Management, 29: 517-536.

Sanner, S., Baldwin, D., Cannella, K. A., Charles, J., \& Parker, L. 2010. The impact of cultural diversity forum on students' openness to diversity. Journal of Cultural Diversity, 17: 5661.

Simons, G. F. 1992. The questions of diversity: Assessment tools for organizations and individuals. Amherst, MA: ODT, Inc.

Sitzmann, T., Brown, K. G., Casper, W. J., Ely, K., \& Zimmerman, R. D. 2008. A review and meta-analysis of the nomological 
network of trainee reactions. Journal of Applied Psychology, 93: 280-295.

Smith, T., Constantine, M., Dunn, T., Dinehart, J., \& Montoya, J. 2006. Multicultural education in the mental health professions: A meta-analytic review. Journal of Counseling Psychology, 53: 132-145.

Sodowsky, G. R., Taffe, R. C., Gutkin, T. B., \& Wise, S. L. 1994. Development of the multicultural counseling inventory: A self-report measure of multicultural competencies. Journal of Counseling Psychology, 41: 137-148.

Stella, C. S. C., Forlin, C., \& Lan, A. M. 2007. The influence of an inclusive education course on attitude change of preservice secondary teachers in Hong Kong. Asia-Pacific Journal of Teacher Education, 35: 161-179.

Stewart, M. M., Crary, M., \& Humberd, B. K. 2008. Teaching value in diversity: On the folly of espousing inclusion, while practicing exclusion. Academy of Management Learning and Education, 7: 374-386.

Stewart, T. L., LaDuke, J. R., Bracht, C., Sweet, B. A. M., \& Gamarel, K. E. 2003. Do the "eyes" have it? A program evaluation of Jane Elliott's "blue-eyes/brown-eyes" diversity training exercise. Journal of Applied Social Psychology, 33: 18981921.

Stewart, T. L., Latu, I. M., Kawakami, K., \& Myers, A. C. 2010. Consider the situation: Reducing automatic stereotyping through situational attribution training. Journal of Experimental Social Psychology, 46: 221-225.

Stroup, C. 1998. Diversity training and gender communication dynamics. Master's thesis, Pennsylvania State University.

Szpara, M. Y., \& Wylie, E. C. 2005. National Board for Professional Teaching Standards assessor training: Impact of bias reduction exercises. Teachers College Record, 107: 803841.

Tajfel, H., \& Turner, J. C. 1986. The social identity theory of intergroup behavior. In S. Worchel \& W. G. Austin, (Eds.), Psychology of intergroup relations, (2nd ed.): 7-24. Chicago, IL: Nelson-Hall.

Thomas, K. M., Tran, N. M., \& Dawson, B. L. 2010. An inclusive strategy of teaching diversity. Advances in Developing $\mathrm{Hu}$ man Resources, 12: 295-311.

Thomas, R. R. 1991. Beyond race and gender: Unleashing the power of your total workforce by managing diversity. New York: American Management Association.
Thomas, R. R. 1996. Managing diversity: A conceptual framework. In S. E. Jackson and Associates, (ed.), Diversity in the workplace: Human Resources Initiatives: 306-319. New York: Guilford Publications.

Thomas, V. J., \& Cohn, T. 2006. Communication skills and cultural awareness courses for healthcare professionals who care for patients with sickle cell disease. Journal of Advanced Nursing, 53: 480-488.

Toporek, R. L., \& Pope-Davis, D. B. 2005. Exploring the relationships between multicultural training, racial attitudes, and attributions of poverty among graduate counseling trainees. Cultural Diversity and Ethnic Minority Psychology, 11: 259-271.

Tran, M. T., Young, R. L., \& Di Lella, J. D. 1994. Multicultural education courses and the student teacher: Eliminating stereotypical attitudes in our ethnically diverse classroom. Journal of Teacher Education, 45: 183-189.

Van Den Bergh, N. 1999. Workplace problems and needs for lesbian and gay male employees: Implications for EAPs. Employee Assistance Quarterly, 15: 21-60.

Vann, B. A. 1996. Learning self-direction in a social and experiential context. Human Resource Development Quarterly, 7: 121-130.

Waddill, D. D., \& Marquardt, M. 2003. Adult learning orientations and action learning. Human Resource Development Review, 2: 406-429.

Wentling, R. M., \& Palma-Rivas, N. 1998. Current status and future trends of diversity initiatives in the workplace: Diversity experts' perspective. Human Resource Development Quarterly, 9: 235-253.

Werner, J. M., \& DeSimone, R. L. 2009. Human resource development. Mason, OH: Cengage/South-Western.

Wiethoff, C. 2004. Motivation to learn and diversity training: Application of the theory of planned behavior. Human Resource Development Quarterly, 15: 263-278.

Wilczenski, F. L. 1992. Measuring attitudes toward inclusive education. Psychology in the Schools, 29: 306-312.

Williams, C. C. 2005. Training for cultural competence: Individual and group processes. Journal of Ethnic and Cultural Diversity in Social Work, 14: 111-143.

Williams, K., \& O'Reilly, C. A. 1998. Demography and diversity: A review of 40 years of research. In B. M. Staw \& L. L. Cummings, (Eds.), Research in organizational behavior, 20: 77-140. Greenwich, CT: JAI Press.

Katerina Bezrukova is an assistant professor of psychology at Santa Clara University. She earned her $\mathrm{PhD}$ at Moscow State (Lomonosov) University. Bezrukova's research interests include workplace diversity and group faultlines, organizational conflict and performance, intergroup and interorganizational relations, and diversity training. Recent projects involve justice, employee health, and technology.

Karen A. Jehn is a professor of organization behavior at Melbourne Business School. Jehn earned her $\mathrm{PhD}$ from Northwestern University. Her research focuses on intragroup conflict, group composition and performance, and lying in organizations. Her two most recent research interests are asymmetry of perceptions and member entitlement in workgroups.

Chester S. Spell is an associate professor of management at Rutgers University. Spell earned his $\mathrm{PhD}$ at Georgia Tech. His interests include behavioral health and organizational justice in work teams. Recent projects involve justice, group diversity and employee mental health, and the alignment of employer interests to improve behavioral health. 
Copyright of Academy of Management Learning \& Education is the property of Academy of Management and its content may not be copied or emailed to multiple sites or posted to a listserv without the copyright holder's express written permission. However, users may print, download, or email articles for individual use. 